\title{
CHARACTERIZATION OF VOLATILE AROMA CONSTITUENTS IN AVOCADOS (PERSEA AMERICANA MILL) GROWN IN SRI LANKA
}

\author{
Thevaki Mahendran \\ Department of Agricultural Chemistry, Faculty of Agriculture, \\ Eastem University, Sri Lanka
}

\begin{abstract}
The volatile components of avocados were isolated by Tenex GC and analysed by capillary Gas Chromatography linked with Mass Spectrometry. A total of 73 components were detected as avocado volatiles, of which 70 compounds comprising $99 \%$ of the isolates were positively identified. Sixteen of the identified compounds have not been previously been reported as avocado volatiles including butanal, oct-1-ene, dimethyl cyclohexane, nonan-2-one and tetradecanoic acid. In ripe avocados, C-6 alcohols and aldehydes were the major group of volatiles with trans-hex-3-en-1-ol as the most abundant constituent of 22.04\%. The C-6 aldehyde, cis-hex-2-enal accounted to $6.66 \%$ of the aroma isolates in the ripe fruits. Terpenoids were the predominant class of constituents in unripe avocados: One monoterpene, limonene (2.97\%) and ten sesquiterpenes were identified, $\beta$-caryophyllene being the major terpene (14.28\%) followed by $\beta$-franescene (10.92\%) and $\alpha$-cubebene $(10.2 \%)$ as the main hydrocarbons. In an olfactory assessment at odour port during GC, six aroma compounds were described possessing the characteristics green flavour of avocado. The C-6 alcohols and aldehydes were significant components of aroma together with several compounds deriving from fatty acid precursors. The oxidative decomposition of carotenoids leads to the formation of terpenoids in unripe avocados.
\end{abstract}

Key words: aroma volatiles, avocado, flavour, odour port analysis, trepenoids

\section{INTRODUCTION}

The avocado (Persea americana Mill) belongs to the family Lauraceae and is one of the major fruit crops in the world. It is native to central America but is grown in all tropical and subtropical regions of the world. During the past decade, the demand for this fruit has increased significantly as a result of increased consumer awareness of fruit's diatery value and improved fruit quality resulting from implementation of maturity standards and improved storage and transportation facilities. In Sri Lanka, avocado is grown in central high lands most often as seedlings among crop plants on estates and in back gardens. The avocado scasons normally exists from April to July when the fruits are relativcly abundant. Avocado is a favorite article of diet in Sri 
Lanka and is mainly consumed in the form of fresh fruit. It is also used as an ingredient in salads and tortillas with lemon juice, pepper and salt.

Avocado is an oleaginous fruit and the lipid content in the mesocarp varies from $12.4-24.2 \%$ at mature ripe stage (Nagalingam, 1994). Because of the high oil content, the fruits have the highest energy value of any fruit. The high oil content also contributes to the consistency and the special taste of the fruit. Unlike the other fruits, the avocado is high in fat, protein, vitamins and minerals but low in sugars; therefore it can be recommended as a high energy food for the diabetic (Swisher et al., 2001). Knowledge of the identities of the constituents which are responsible for avocado flavour is important for the control of flavour, both in the fresh and processed products.' The high oil content of the fruit has attracted special attention with respect to composition of fruit but relatively little work has been done on the composition of the volatile constituents of avocado fruit and therefore the present study was undertaken to characterize the volatile aroma components of avocados.

\section{MATERIALS AND METHODS}

\section{Avocado Samples}

Fresh, locally harvested Avocado fruits cv. Hass were obtained from a commercial grower at Kandy, Sri Lanka. Fruits were washed with water and dried in the air before use. Fruits were ripened in a humidity control cabinet at $20^{\circ} \mathrm{C}$ and the $\mathrm{RH}$ of $90-94 \%$. To obtain such humidity level, the air pump was used to bubble the air through water in a tray. Each day, the stages of ripening of fruits were determined subjectively by applying gentle pressure to the fruit held the palm of the hand. Categories were hard, soft and ripe. These stages were confirmed by texture measurement using Steven's Compression Response Analyzer using $50 \mathrm{~kg}$ load cell. Fruits at different ripening stages were halved longitudinally and the seeds removed. Hard fruits were peeled and the flesh put through a food shredder. For soft and ripe fruits, the pulp was scrapped and homogenized for $5 \mathrm{~min}$.

\section{Isolation of Volatiles}

A weighed quantity of $300 \mathrm{~g}$ sample from 3 avocados was transferred to an aroma isolation apparatus witl a screw top containing both an inlet and outlet tubes. The flask was placed in a water bath at $40^{\circ} \mathrm{C}$. A SGC trap, containing Tenax-GC (polymer of 2, 6 diphenyl- $P$-phenylene) as the absorbent, was connected to the outlet and a oxygen free nitrogen was connected to the inlet. The nitrogen was passed over the pulp at a flow rate of $40 \mathrm{ml} / \mathrm{min}$ for 1 hour and the avocado volatiles were swept onto the trap. The inlet was also connected to a tube containing an absorbent (charcoal) to prevent volatiles from the gas supply reaching 
the trap. At the end of collection time, the flask was removed and the trap was connected directly to the nitrogen supply at the same flow rate for 5 min to remove the moisture. A blank isolate was also prepared using an empty isolation apparatus. Alkanes standards $\left(\mathrm{C}_{6}\right.$ to $\left.\mathrm{C}_{25}\right)$ were used in the measurement of retention indices of the standard and the compounds separated from avocados. Ethanol, ethyl acetate, hexanal, nonanal, hexan-1-ol, hex-2-en-1-ol, hex-3-en-1-ol and $\beta$-pinene were purchased from BDH Chemicals, $\mathrm{UK}$ and $\beta$-caryophyllene, $\alpha$-cubebene, $\beta$-franescene and $\alpha$-humulene from Aldrich Chemical Ltd, UK.

\section{Gas Chromatography Analysis of Volatiles}

A Perkin-Elmer Sigma 3B equipped with flame ionization detector (FID) was used for routine gas chromatographic analysis. A fused silica capillary column of $60 \mathrm{~m}$ x $0.32 \mathrm{~mm}$ I.D., coated with $1 \mu \mathrm{m}$ film thickness of $95 \%$ dimethyl siloxane $+5 \%$ phenyl siloxane (SE 52/54) bonded phase was used to separate the volatile components. The trap was placed directly in the injection port of the gas chromatograph and its contents were desorbed with the helium carrier gas at the flow rate of $1.5 \mathrm{ml} / \mathrm{min}$ for $5 \mathrm{~min}$ onto the front end of the capillary column. The column was cooled to $0^{\circ} \mathrm{C}$ with liquid $\mathrm{CO}_{2}$ which entered the oven through a metal tube, surrounding the column. After desorption the oven was heated rapidly to $30^{\circ} \mathrm{C}$, followed by heating at $3^{\circ} \mathrm{C} / \mathrm{min}$ to $250^{\circ} \mathrm{C}$. The column temperature was maintained at $250^{\circ} \mathrm{C}$ until the completion of the separation. The injector port and the detector temperature were maintained at $250^{\circ} \mathrm{C}$ and $260^{\circ} \mathrm{C}$, respectively. A Hewlett Packard model-3390A reporting integrator was used to determine the peak area during routine analysis. Linear retention indices for the volatile components were calculated by chromatographing $\mathrm{n}$ alkanes $\left(\mathrm{C}_{6}\right.$ to $\left.\mathrm{C}_{25}\right)$ mixed with the samples. Linear retention indices for the authentic aroma compounds were similarly determined.

\section{Gas Chromatographic-Odour Port Analysis}

Aromas of the separated components were assessed at the column outlet during the chromatographic separation using the technique of GC-Odour port assessment. Chromatographic efluents were split in a ratio of $1: 1$ by means of the outlet splitter containing a two fold vespel ferrule, such that two equal lengths of deactivated fused silica $(0.3 \times 0.32 \mathrm{~mm}$ I.D. $)$ led from the ferrule, one length of the GC detector and the other length of the external sniffing port. 'The odours of the separated components were described by two assessors experienced in descriptive analysis of odours. Triplicate assessments were performed for each ripening stages of avocados.

\section{Gas Chromatographic-Mass spectrometric Analysis of Volatiles}

Volatile components were identified as far as possible by Gas Chromatography - Mass Spectrometry 
analysis using a Kratos MS 80RFA Mass Spectrometer linked on line to a Kratos DS 90 data processing system coupled to a Carlo-Erba 5300 Gas Chromatography. The same GC conditions were used in this instrument. The significant operating parameters were: ionization voltage - $70 \mathrm{eV}$; Emission current $-100 \mu \mathrm{A}$; Ion source temperature $-200^{\circ} \mathrm{C}$; Accelerating voltage $-4 \mathrm{KV}$; Resolution - 1000; Scan speed $-1 \mathrm{~s} f$ decade; Scan time $-0.2 \mathrm{~s}$.

\section{Component Identification and Quantitative Assessment}

Interpretation of Mass Spectra was done by computerized data matching, using libraries on the GC-MS data systems (Eight Peak Index of the Mass Spectra) and by manual comparisons with published mass spectra. Identifications were confirmed by comparing the Linear Retentive Indices (LRI) or Covats Index of each component. The mass spectra and retention indexes of compounds which were not available, were matched, where possible with values recorded in the literature.

Quantitative data were derived from the TIC monitor obtained during GC - MS and for trace components by extrapolation from integrator (Hewlett Packard 3370B) data obtained from the GC-FID chromatogram recorded during routine GC analysis. Triplicate analyses were performed.

\section{RESULTS AND DISCUSSION}

Components identified in headspace concentrates from avocado samples at three ripeness stages are listed in Table 1 . Overall 73 components were detected as avocado volatiles, of which 70 compounds comprising $99 \%$ of the samples were positively identified. The three unidentified compounds were present in the sample in such low amounts that no mass spectrum could be recorded. Changes in individual volatiles during ripening were also assessed. In ripe fruits, the isolates were dominated by C- 6 alcohols and aldehydes but terpenes were the abundant classes of volatiles in unripe fruits.

In avocados, the levels of C-6 alcohols and aldehydes remarkably increascd during ripening. Three C-6 alcohols were present at high concentration in ripe fruits. The predominant alcohol is trans-hex-3-en-1-0l which accounts $22.04 \%$ in the ripe fruits. The geometric isomer, trans-hex-2-en-1-ol is present at about $17.43 \%$. In unripe fruits, these two components are present at $7.71 \%$ and $4.21 \%$ respectively. No work appears to have been published on the changes in volatile constituents during ripening of avocados. However, only two reports are available on the volatile components of avocados. Yamaguchi (1989) reported that trans-hex-2-en-1-ol and hexan-1-ol comprised 58.95\% and $9.82 \%$ in the ripe avocado isolate but the variety of the avocado examined was not mentioned. They also reported the presence of low levels of 
hexanal $(0.39 \%)$ and trans-hex-2-enal (1.61\%) in their isolates. This is in contrast with our findings where hexanal was present $5.51 \%$ and trans-hex-2-enal was not identified as a component of the aroma isolate. Compared to hexanal and cis-hex-2-enal, the concentration of trans-hex-3-enal was found to be low at $0.37 \%$ in ripe fruits. According to the work of Kazeniac and Hall (1990), the formation of some of the cishex-2-enal is through trans-hex-3-enal by the action of enzyme isomerase. It is well known that this type of double bond shift occurs readily. Because of this double bond shift, it is difficult to get an accurate analysis of the relative amount pf each compound as it occurs in the avocado.

The quantity and quality of C-6 alcohols and aldehydes is dependant on the amount of oxygen in the sample, enzyme activity, extent of comminution, isolation procedure and the extent of heat. Therefore, some of the aldehydes may be transformed to alcohols by enzymatic action. Since blending effectively disintegrates the avocado tissues, the natural enzymes and their substrates are intimately mixed. In addition, an excess air is whipped into the mixture during blending the pulp. The combination of these factors would be expected to greatly favour the development of flavour compounds by enzymatic oxidation (Whitefield $e t$ al., 1980).

The domination of aroma isolates from ripe avocado, by C- 6 alcohols and aldehydes appears to be unique among tropical fruits. These two classes of compounds accounted over $65 \%$ of the total aroma isolates and the characteristics flavour come from the $\mathrm{C}-6$ alcohols and aldehydes. In wide range of plant tissues, the carbonyl compounds are derived from the reaction of fatty acids with oxygen and lipoxygenase enzyme. The dominant compounds identified in the ripe avocado aroma are reported to be derived from fatty acid degradation. Avocaods are known to be rich in oil. The average oil content of unripe and ripe fruits used in this study was $15.4 \%$ and $21.1 \%$ respectively. Several authors examined the formation of C-6 alcohols and aldehydes from unsaturated fatty acids. (Stone et al., 1999 and Galliard et al., 2001).

Investigating the fatty acid composition of lipids in Hass avocados, the unsaturated fatty acids such as oleic acid $-70.2 \%$, linoleic acid $-10.1 \%$ and linolenic acid $-1.03 \%$ were found to prevail in the ripe fruits (Mahendran and Thireganathan, 1998). On maceration of tissues, enzymatic decomposition of lipid proceeds very rapidly. Kazeniac and Hall (1990) showed that in the presence of $\mathrm{H}^{+}$and under the influence of heat, cis-hex-3-enal is transformed into trans-hex-2-enal isomer. These aldehydes may be converted to C-6 alcohols by the enzyme alcohol dehydrogenase during storage and ripening of fruits. 
Table 1: Aroma Compounds of Avocado (Persea americana Mill)

\begin{tabular}{|c|c|c|c|c|c|c|}
\hline \multirow[t]{2}{*}{ Compound } & \multirow{2}{*}{$\begin{array}{l}\text { Retention } \\
\text { (Time min) }\end{array}$} & \multirow[t]{2}{*}{$\mathbf{L R I}^{\dagger}$} & \multicolumn{3}{|c|}{$\%$ Relative abundance * } & \multirow{2}{*}{$\begin{array}{l}\text { Odour }^{\S} \\
\text { quality }\end{array}$} \\
\hline & & & Unripe & Soft & Ripe & \\
\hline Acetaldehyde & 2.57 & 368 & 0.78 & 2.04 & 3.94 & Fragrant, floral \\
\hline Ethanol & 5.23 & 512 & 5.51 & 6.21 & 7.44 & Sweet \\
\hline 2-Propanol & 7.82 & 522 & 0.49 & 0.41 & 0.21 & \\
\hline Acetone & 8.07 & 527 & $\operatorname{tr}$ & $\operatorname{tr}$ & 0.20 & Yeasty, fruity \\
\hline Diethyl ether & $\because 8.36$ & 530 & $\operatorname{tr}$ & $\operatorname{tr}$ & $\operatorname{tr}$ & \\
\hline Penta-1-3-diene & 9.25 & 540 & $\operatorname{tr}$ & $\operatorname{tr}$ & $\operatorname{tr}$ & Stale grass \\
\hline Methyl acetate & 10.40 & 543 & 0.44 & 0.91 & 1.21 & \\
\hline 2-Methyl propanal & 12.49 & 550 & 0.24 & 0.74 & 0.83 & Floral, sweet \\
\hline 2-Methyl pentane & 14.80 & 557 & 0.45 & 0.40 & 0.01 & \\
\hline 3-Methyl pentane & 14.97 & 562 & 1.14 & 1.01 & 0.18 & Roasted cereal \\
\hline Propanol & 15.21 & 569 & 1.12 & 1.17 & 1.29 & \\
\hline Unknown & 15.60 & 577 & tr & $\operatorname{tr}$ & 0.09 & \\
\hline Di acetal & 15.97 & 584 & 0.12 & 0.14 & 0.17 & Buttery \\
\hline Butanal & 16.81 & 592 & 0.34 & 0.41 & 0.54 & \\
\hline Hexane & 17.05 & 598 & 0.18 & 0.32 & 0.35 & \\
\hline 2-Methyl furan & 17.24 & 606 & $\operatorname{tr}$ & $\operatorname{tr}$ & 0.10 & \\
\hline Ethyl acetate & 18.12 & 612 & 1.22 & 1.91 & 2.44 & Fruity \\
\hline Methyl cyclopentane & 18.64 & 619 & 0.10 & 0.15 & 0,19 & \\
\hline 2-Methyl-1-propanol & 19.04 & 628 & 0.21 & 0.20 & 0.07 & Sweet \\
\hline 3-Methyl butanal & 19.51 & 651 & 0.29 & 0.17 & 0.08 & Fragrant \\
\hline 2-Methyl butanal & 20.01 & 660 & $\operatorname{tr}$ & $\operatorname{tr}$ & $\operatorname{tr}$ & Sweet (mango) \\
\hline 2, 4-Dimethyl pentane & 20.43 & 674 & 0.22 & 0.32 & 0.35 & \\
\hline Pentanal & 20.74 & 689 & 0.09 & 0.26 & 0.32 & Pungent \\
\hline 3-Pentanone & 21.45 & 691 & 0.10 & 0.41 & 0.60 & \\
\hline 3-Pentanol & 21.53 & 692 & 0.12 & 0.12 & 0.14 & \\
\hline 2-Ethyl furan & 23.06 & 700 & $\operatorname{tr}$ & $\operatorname{tr}$ & $\operatorname{tr}$ & Fragrant, caramel \\
\hline 3-Methyl butanol & 23.27 & 722 & 0.21 & 0.41 & 0.77 & \\
\hline 3-Hydroxy-butan-2-one & 24.33 & 731 & 0.12 & 0.19 & 0.26 & \\
\hline 2-Methyl butanol & 25.46 & 733 & 0.29 & 0.51 & 0.72 & Floral fragrant \\
\hline Pentan-1-ol & 26.16 & 760 & $\operatorname{tr}$ & $\operatorname{tr}$ & $\operatorname{tr}$ & \\
\hline Toluene & 26.30 & 767 & 0.24 & 0.20 & 0.01 & Chemical solvent \\
\hline Oct-1-ene & 26.69 & 792 & 0.18 & 0.24 & 0.29 & \\
\hline Trans-hex-3-enal & 27.05 & 798 & 0.12 & 0.19 & 0.37 & Green, fruity \\
\hline Hexanal & 27.14 & 799 & 1.82 & 3.31 & 5.51 & Green, grassy \\
\hline Dimethyl cyclohexane & 27.14 & 801 & 0.19 & 0.36 & 0.40 & \\
\hline Octane & 27.36 & 809 & 0.31 & 0.56 & 0.59 & \\
\hline Trimethyl cyclohexane & 27.61 & 812 & 0.04 & 0.26 & .0 .30 & \\
\hline Furfural & 27.70 & 817 & 0.21 & 0.35 & 0.42 & \\
\hline
\end{tabular}




\begin{tabular}{|c|c|c|c|c|c|c|}
\hline \multirow[t]{2}{*}{ Compound } & \multirow{2}{*}{$\begin{array}{c}\text { Retention } \\
\text { Time (min) }\end{array}$} & \multirow[t]{2}{*}{$\mathbf{L R I}^{\dagger}$} & \multicolumn{3}{|c|}{ \% Relative abundance* } & \multirow{2}{*}{$\begin{array}{l}\text { Odour }^{\S} \\
\text { quality }\end{array}$} \\
\hline & & & Unripe & Soft & Ripe & \\
\hline Cis-hex-2-enal & 30.59 & 847 & 2.38 & 4.29 & 6.66 & Green, fruity \\
\hline Trans-hex-3-en-1-ol & 30.63 & 856 & 7.71 & 19.60 & 22.04 & Green, floral \\
\hline Trans-hex-2-en-1-ol & 31.49 & 860 & 4.21 & 13.76 & 17.43 & Green, fruity \\
\hline Hexan-1-ol & 32.45 & 866 & 3.04 & 10.47 & 13.71 & Green, fragrant \\
\hline Heptanal & 33.98 & 884 & 0.22 & 0.61 & 0.81 & Caramel, buttery \\
\hline Nonane & 34.20 & 898 & 0.20 & 0.19 & 0.16 & Sweet. \\
\hline Nonan-2-one & 36.27 & 927 & 0.19 & 0.17 & $\operatorname{tr}$ & Fragrant \\
\hline 5-Methyl furfural & 36.89 & 939 & 0.22 & 0.47 & 0.49 & \\
\hline$\beta$-Pinene & 37.32 & 949 & 2.69 & 1.48 & $\operatorname{tr}$ & \\
\hline Ethyl benzene & 38.04 & 968 & 0.41 & 0.99 & 1.08 & \\
\hline 2-Methyl-5-hepten-2-one & 40.86 & 990. & 0.21 & 0.15 & 0.04 & Musty \\
\hline Octanal & 41.07 & 991 & 0.37 & 0.51 & 0.74 & Sweet, fruity \\
\hline Tri methyl benzene & 41.17 & 1002 & 0.11 & 0.15 & 0.17 & \\
\hline Limonene & 43.29 & 1036 & 2.97 & 1.71 & $\operatorname{tr}$ & Sweet, fragrant \\
\hline Unknown & 43.71 & 1042 & 0.05 & 0.07 & 0.11 & \\
\hline Nonanal & 47.28 & 1087 & 1.32 & 2.14 & 2.90 & Fruity (pcach) \\
\hline Decanal & 54.20 & 1186 & 1.42 & 1.51 & 1.74 & Orange peel. \\
\hline Dodecane & 56.24 & 1200 & $\operatorname{tr}$ & $\operatorname{tr}$ & $\operatorname{tr}$ & \\
\hline$\alpha$-Cubebene & 67.31 & 1269 & 10.20 & 4.64 & 0.24 & \\
\hline$\alpha$-Copaene & 69.21 & 1386 & 4.86 & 0.71 & $\operatorname{tr}$ & \\
\hline$\beta$-Franescene & 69.94 & 1402 & 10.92 & 0.41 & $\operatorname{tr}$ & \\
\hline$\beta$-Caryophyllene & 70.42 & 1421 & 14.28 & 7.20 & 0.12 & Slight burnt. \\
\hline$\beta$-Gurjunene & 72.38 & 1476 & 4.57 & $\operatorname{tr}$ & $\operatorname{tr}$ & \\
\hline Calarene & 73.04 & 1504 & 3.28 & 1.20 & 0.11 & \\
\hline$\delta$-Cadinene & 75.24 & 1524 & 3.74 & 1.11 & tr & \\
\hline Tetra decanal & 76.04 & 1582 & 0.21 & 0.14 & 0.09 & Oily, fatty, rancid \\
\hline$\alpha$-Humulene & 76.21 & 1624 & 2.07 & 1.00 & 0.12 & Fruity (guava) \\
\hline$\delta$-Elemene & 77.40 & 1729 & 0.76 & 0.70 & 0.12 & Leathery \\
\hline Unknown & 79.04 & 1803 & $\operatorname{tr}$ & 0.04 & 0.09 & \\
\hline Tetradecanoic acid & 81.92 & 1894 & 0.02 & 0.14 & 0.17 & Slight oily, waxy. \\
\hline Nonadecane & 82.24 & 1909 & 0.21 & 0.14 & $\operatorname{tr}$ & \\
\hline Eicosane & 83.74 & 1986 & 0.17 & 0.12 & 0.11 & Musty / mouldy \\
\hline 3-Methyl octadecane & 84.87 & 1993 & 0.02 & 0.07 & 0.09 & \\
\hline$\delta$-lactone & 86.01 & 2018 & $\operatorname{tr}$ & $\operatorname{tr}$ & 0.02 & \\
\hline Heneicosane & 87.56 & 2039 & 0.04 & 0.20 & 0.22 & \\
\hline
\end{tabular}

* Relative percentage of total peak area.

Values are means of 3 replications correlated to nearest $0.01 \%$, if $<0.001 \%$ then quoted as trace (tr). ${ }^{+}$Linear Retention Indices (LRI) calculated for the SE52/54 capillary column of the GC-MS system.

${ }^{\circledR}$ By GC-Odour port assessment. 
Alcohols, a part from C- 6 compounds, accounted for about $8 \%$ and $11 \%$ of the isolates obtained from the unripe and ripe fruits respectively. Similarly, total aldehydes proportions of the isolates other than C-6 compounds accounted about $5 \%$ and $12 \%$ in the unripe and ripe fruits respectively. The level of acetaldehyde increased from $0.78 \%$ to $3.94 \%$ during ripening of avocados. The concentration of ethanol was higher than that of acetaldehyde suggesting a rapid conversion of acetaldehyde to ethanol by enzymatic action. Apart from acetaldehyde, nonanal and decanal are reputed to be important volatile constituents in avocado. Moreover, 2-methyl propanal, butanal, 3-methyl butanal, 2-methyl butanal, pentanal, heptanal, and octanal were also identified. The total amount of aldehydes concentration of avocado increased with progressive ripening. The amino acid profile of avocado has been reported by (Ahmed and Barmore, 1983) and strecker degradation of alanine, valine, leucine and isoleucine explains the formation of acetaldehyde, 2methyl propanal, 2-methyl butanal and 3-methyl butanal, respectively. Many of the aldehydes identified in this study can be related to the major groups of the non-volatile constituents found in fruits. The straight chain saturated and unsaturated aldehydes are fairly typical of those formed from oxidative degradation of the fatty acids. These are common to many fruits although each fruit appears to have its own relative proportions of the different volatile constituents.

Aliphatic ketones account less than 2\% in the ripe and unripe isolates. Acetone, 3-pentanone, 3hydroxybutan-2-one, nonan-2-one and 2-methyl-5-hepten-2-one were identified in both ripe and unripe fruits. The number of esters identified in this study is limited. The level of esters is nearly $4 \%$ and $2 \%$ in the ripe and ünripe fruits respectively. Methyl acetate and ethyl acetate are the only two esters identified from both isolates. These two esters commonly occur in aroma volatiles of many tropical fruits including avocados (Kader, 1989). As the endogenous level of acetaldehyde and ethanol increased, the concentration of methyl acetate and ethyl acetate were found to increase during ripening. The levels of these two esters remained high at edible ripe stage. This may indicate the biosynthesis of these two esters continues with progressive ripening, as happened with other esters in apples treated with carboxylic acids. Apples were found to produce carboxylic esters from added aliphatic volatile alcohols and acids apparently by absorbing the alcohols and acids from the surrounding atmosphere and converting them into esters which were released into the atmosphere again. (De Potter et al., 2003). As an effect of non-enzymatic browning reaction between the reducing sugars and amino acids upon heating, volatile carbonyl compounds are formed and these may highly affect the character of aroma. In avocado, these compounds were identified as furfurals, 2-methyl furan and 2-ethyl furan.

The most important aroma constituents of unripe avocadoes are terpenes. These compounds comprise over $60 \%$ of the total volatiles. In ripe fruits these compounds are present at a total level less than $1 \%$. One 
monoterpene hydrocarbon, limonene (2.97\%) and ten sesquiterpene hydrocarbons were identified from both ripe and unripe isolates. The major sesquiterpene hydrocarbon identified in this study was $\beta$ caryophyllene which accounts $14.28 \%$ in the unripe fruits and the levels decreased to $0.12 \%$ with progressive ripening (Figure: 1). Stevens et al (1999) reported that $\beta$-caryophyllene was the major sesquiterpene hydrocarbon component identified from guava. Softening results in a considerable relative decrease in the concentrations of $\alpha$-cubebene and $\beta$-farnescene. Other terpene hydrocarbons which have been identified to contribute aroma of unripe avocados were $\alpha$-copaene $(4.86 \%)$, $\beta$-gurjunene $(4.57 \%)$, calarene $(3.28 \%)$, $\delta$-cadinene $(3.74 \%)$ and $\alpha$-humulene (2.07\%). Young et al (1999) found no sesquiterpenes in ripe avocado mesocarp extracted under the reduced pressure, but found 2-methyl-2-butanal, dimethyl formaldehydc and methanol which were not found in this study.

The normal flavour of avocado fruit is usually described as bland with a green and peppery after taste. The characteristics green flavour is due to presence of C- 6 alcohols and aldehydes which comprises over $65 \%$ of the total aroma isolates in ripe fruits. The likely cause of peppery flavour is at present unknown but atleast three of the sesquiterpenes hydrocarbons, $\beta$-caryophyllene, $\alpha$-cubebene and $\alpha$-copaene could impart a distinctive flavour to the rather bland tasting flesh of the avocado. Some of the identified volatiles are derived from the non-lipid precursors. The oxidative decomposition of carotenoids leads to the formation of terpene compounds.

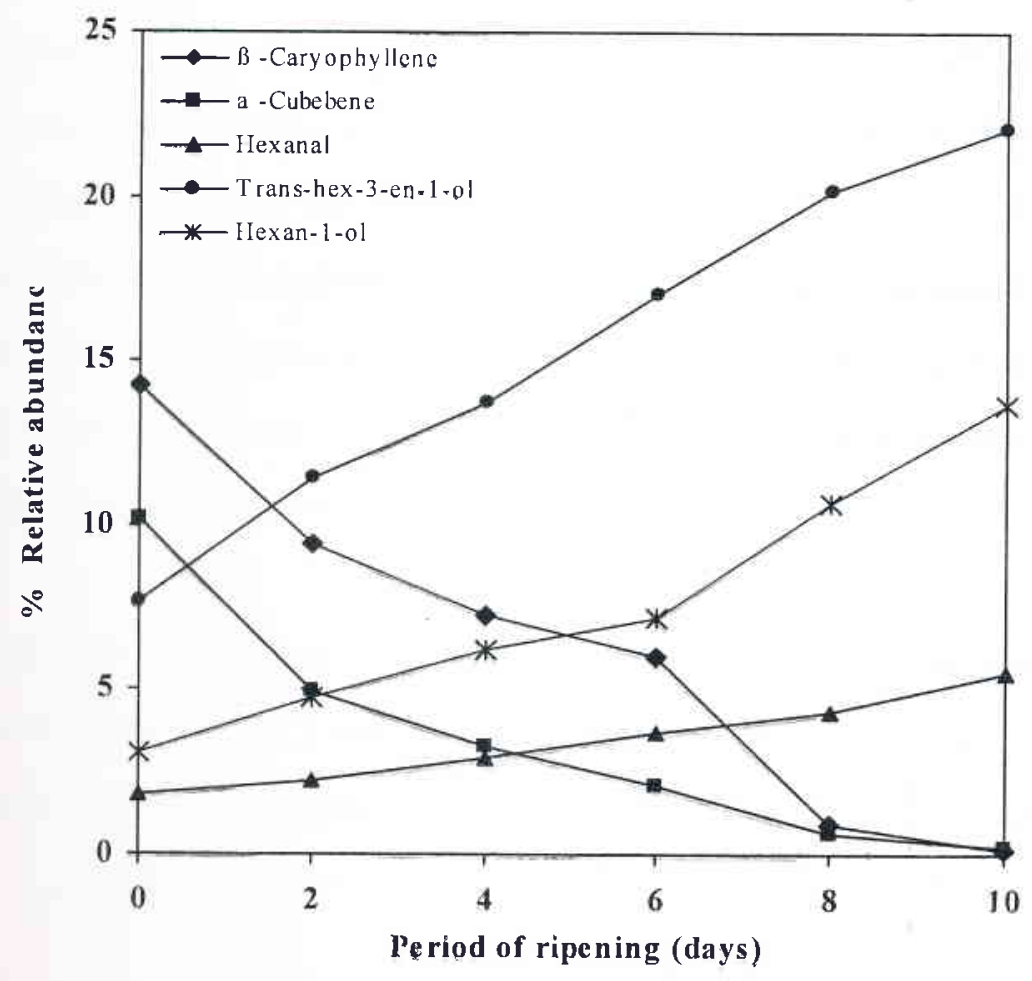

Figure 1: Changes in pre-dominant volatile constituents during ripening of avocados at $20^{\circ} \mathrm{C}$ 
The carotenoid content of avocados cv. Hass was determined recently as $18 \mu \mathrm{g} / \mathrm{g}$ fresh fruit. Onyewn and co-workers (1996) surveyed derivatives of carotenoids (particularly $\beta$-carotene) formed upon heat treatment and identified one of them as toluene. Avocado contains phospholipids, glycolipids and triacylglycerol which are rich in linoleic acid and linolenic acid. On rupture of cclls, these fatty acids aıc released by the action of acyl hydrolases and phospholipase $D$ and are further converted by lipoxygenase into the 9 - and 13-hydroperoxides of both linoleic and linolenic acids. The volatile cleavage product is hexanal when 13hydroperoxy linoleic acid is the substrate while cis-hex-2-enal is produced on cleavage of 13-hydroperoxy linolenic acid. Previous work in this (Young et al., 1999) had cstablished that homogenization of avocado tissue caused the conversion of linoleic and linolenic acid to volatile carbonyl fragments.

In this study, as expected, a large number of volatile compounds were obtained in addition to terpenes, especially compourds relating from lipid degradation products which included alcohols and aldehydes. Partly because of the enzymatic procedures instantaneously occurring upon the maceration of the fruit, it is difficult to establish which of the volatile components were present originally in the fruit and which developed during the comminution and homogenization. In addition to the compounds identified, avocado extracts contained a number of related higher molecular weight compounds which are probably complexes of substituted phenols and studies to identify these continue.

\section{CONCLUSIONS}

The characteristics green flavour of avocado is due to the presence of $\mathrm{C}-6$ alcohols and aldehydes which comprises over $65 \%$ of the total aroma isolates at ripe stage. Terpenes are the important aroma constituents of unripe avocados and expected to contribute a peppery after taste. A greater number of alcohols and carbonyl compounds identified in aroma isolates are classic volatiles produced derived from fatty acid oxidation and degradation. Olfactory assessments of odour port during GC six peaks were described as possessing significant green note of avocado flavour.

\section{REFERENCES}

Ahmed, E. M. and Barmore, C. R. (1983) Avocado. In: Nagy, S. and Shaw, P. E. (Eds.) Tropical and Subtropical Fruits: Composition, Properties and Uses. 132-156. AVI Publishing Co., USA. De Potter, H. L., Montens, J. P. and Dickson, M. (2003). Trealments of Golden Delicious apples with acetaldehydes and carboxylic acids. J. Agric. Food Chem: 54: 756-769. 
Galliard, M. G., Mathew, H., Fishwick, H. A. and Frank, U. P. (2001). The enzymatic breakdown of lipids to volatiles and non-volatile carbonyl fragments in disrupted tomato fruits. J. Sci. Food and Agric. 66: 823-830.

Kazeniac, S. J. and Hall, R. M. (1990). Flavour chemistry of tomato and tomato products. J. Food Sci. 55: $519-527$.

Kader, A. A. (1989). Composition and flavour quality of fresh fruits as influenced by some postharvest handling procedures. J. Amer. Soc. Hort. Sci. 117: 117-129.

Mahendran, T. and Thireganathan, V. (1998). Effect of cold storage on ripening, chilling injury and quality of avocado fruit. Proc of the Sri Lanka Association for the Advancement of Science. 54:115.

Nagalingam, T. (1994) Avocados. In. Encyclopedia of Food Science, Food Technology

and Nutrition. Academic press, 289-294. Eds: Macrae, R., Robinson, R. K. and Sadler, M. J. Academic Press, UK. 230-236.

Onyewn, L. Y., Daun, H. and Caserett, K. O. (1996). Formation of thermal degradation products of $\beta$ carotene. J. Agric. Food Chem. 44: 89-94.

Stevens, K. L., Brekke, J. E. and Stern, K. W. (1999). Volatile constituents in Guava. Phytochem. 38: 338-347.

Stone, C. K. Hall, M. and Kazeniac, U. L. (1999). Formation of aldehydes and alcohols in tomato fruit from ${ }^{14} \mathrm{C}$-labelled linoleic and lenolenic acids. J. Food Sci. 68: 1102-1112.

Swisher, C. U., Lyons, H. N. and Robinson, J. (2001). Seasonal variation in the composition of avocados. J. Agric. Food Chem. 50: 1104-1117.

Whitefield, F. B., Last, J. H., Chaplin, G. and Bannister, P. A. (1980). Volatile flavour components of the fruit of avocado. Proc. $8^{\prime \prime}$ Int. Cong. Essential Oils. 349-352.

Yanaguchi, K. (1989) Bio-chemical Composition of Tropical Fruits. In: Charalambus, G. and Inglett, 'H. (Eds.) Instrumental Analysis of Foods. 2: 93-117, Academic Press, UK.

Young, R. E., Nishimura, T. L. and Toda, O. (1999). Effects of phospholipid on the formation of volatile heterocyclic compounds during ripening of avocados. Food Technology Australia. 44: 109-120. 